A Text-Book of Inorganic Chemistry

Edited by Dr. J. Newton Friend. Vol. 6, Part 4: Arsenic. By Reece H. Vallance. Pp. xxxi+351. (London: Charles Griffin and Co., Ltd., 1938.) 25s. net.

$\mathrm{T}$ HIS volume of a well-known text-book deals fully with the inorganic chemistry of arsenic. A special feature is the detailed description of the industrial preparation and uses of the various arsenic compounds. In most cases, sufficient detail is given of the experimental methods to make it possible to repeat them in the laboratory, a notable case being the preparation of arsenic hydride. The information is critically presented and is up to date. Very full references to the literature are given, and very few, if any, important papers can have been missed. The physico-chemical aspect is well represented, as, for example, in the very clear account of the rather difficult subject of the forms of arsenious oxide. The section on analysis is brief but full of useful information.

The volume shares with its companions the valuable feature of being equally suitable for reading by advanced students and as a work of reference. It speaks highly for the skill of the author that he has achieved this result, and the volume is one which should be in every chemical library. The editor announces in the preface that the original scheme of the whole work is now complete and that a new edition is in preparation in which, where the amount of new work justifies it, a separate book will be devoted to each element.

\section{Electron and Nuclear Physics}

By Prof. J. Barton Hoag. Second edition of "Electron Physics". Pp. $x+502$. (London : Chapman and Hall, Ltd., 1938.) 20s. net.

7 HIS is the second edition of the well-known "Electron Physics", which appeared in 1929. It is a remarkably up-to-date summary of the experimental aspects of atomic physics, with a bare minimum of the essential theory. Descriptions are given of nearly forty experiments which are suggested as suitable laboratory exercises; perhaps the most ambitious of these is an experiment on the disintegration of lithium by $50-70$ kilovolt protons. It is obviously not the author's intention that any one student should work through the whole of the experiments, but there are very fow students who could not learn a great deal by merely reading the detailed instructions and working out some of the numerical problems in this book. The text abounds in valuable practical hints, and in addition there are four special chapters on laboratory techniques (including high-vacuum, small-current, counter and high-voltage practice).

The text suffers frequently in elegance, and occasionally in clarity, from the concentration of so much matter into so small a bulk. This is, however, a most valuable book for the young physicist, and the reader is left with the impression that the physics students of the University of Chicago are singularly fortunate in the enthusiasm of their teachers and the equipment of their laboratories.

\section{The Statesman's Year-Book}

Statistical and Historical Annual of the States of the World for the Year 1939. Edited by Dr. M. Epstein. Seventy-sixth annual Publication : Revised after Official Returns. Pp. xxxviii +1508. (London : Macmillan and Co., Ltd., 1939.) 20s. net.

7 HIS indispensable statistical survey of the world follows its customary arrangement and once again in some fifteen hundred pages records an amazing array of facts. The British Empire and the United States fill the first two parts of the book, while the remainder - about one half in actual pagesis occupied by other States arranged in alphabetical order. As a rule the book is revised to March in the year of publication and so two European States appear as independent which have since lost that status. The careful revision of statistics from official sources gives this volume an authoritative standing which should make it invaluable in these days when world affairs are much in discussion and factual information is most desirable. Lists of official and unofficial books dealing with each State are a most useful aspect of the volume. There are coloured maps of Central Europe and of the country traversed by the remarkable Burma-China road between Lashio and Chung-king.

\section{Concise School Physics}

Electricity and Magnetism. By R. G. Shackel. Pp. viii +467-66l. (London, New York and Toronto : Longmans, Green and Co., Ltd., 1938.) 2s. $9 d$.

7 HIS is the third and final part of "A Concise School Physics", which is also available in a single volume. It carries the story well up to matriculation stage and contains 144 pages of copiously illustrated descriptive matter, about 34 pages of questions and answers, and four of mathematical tables. The general treatment follows good conventional practice and the writing is very condensed, so that the book reads like copious notes of excellent lectures supported by adequate laboratory work. The author, avoiding educational fads, has obviously striven to make his difficult story as straightforward as possible for beginners. The book is amazingly cheap at the price and it should prove very useful in class work which is being directed by a capable teacher.

\section{Introduction to Physiological Chemistry}

By Dr. Meyer Bodansky. Fourth edition. Pp. ix + 686. (New York: John Wiley and Sons, Inc.; London: Chapman and Hall, Ltd., 1938.) 20s. net. Laboratory Manual of Physiological Chemistry

By Prof. Meyer Bodansky and Prof. Marion Fay. Fourth edition. Pp. vii +295. (New York : John Wiley and Sons, Inc.; London : Chapman and Hall, I.td., 1938.) 10s. net.

DROF. BODANSKY undoubtedly has a flair for 1 writing studęnts' text-books. These two volumes form a pair-theory and practical-suitable for senior medical students or for those taking degree courses in biochemistry or physiology. Both works are now in their fourth edition and are exceptionally good.
J. C. D. 